\title{
The Protective Role of Endogenous Estrogens in Carrageenan-Induced Lung Injury in the Rat
}

\author{
Salvatore Cuzzocrea, ${ }^{1}$ Emanuela Mazzon, ${ }^{2}$ Lidia Sautebin, ${ }^{3}$ Ivana Serraino, ${ }^{1}$ Laura Dugo, ${ }^{1}$ \\ Giusi Calabró, ${ }^{1}$ Achille P. Caputi, ${ }^{1}$ and Adriana Maggi ${ }^{4}$ \\ ${ }^{1}$ Institute of Pharmacology, University of Messina, Messina, Italy \\ ${ }^{2}$ Department of Biomorphology, School of Medicine, University of Messina, Messina, Italy \\ ${ }^{3}$ Department of Experimental Pharmacology, University "Federico II", Naples, Italy \\ ${ }^{4}$ Institute of Pharmacology Sciences, University of Milano, Milan, Italy \\ Accepted March 5, 2001
}

\begin{abstract}
Background: We have recently demonstrated that $17 \beta$ estradiol (E2) inhibits the increase of inducible nitric oxide synthetase (iNOS) activity in selected model systems such as macrophages, microglia, smooth muscle cells, and proposed that this effect might be associated with an antiinflammatory activity of this hormone. Here we investigate the effects of endogenous estrogens in rats subjected to carrageenan-induced pleurisy.

Materials and Methods: Adult female rats were ovariectomized 3 weeks before the experiments to deplete circulating estrogens. Selected inflammatory markers, landmarks of the delayed phase of carrageenan-induced pleurisy, were measured in intact (N-OVX), and ovariectomized (OVX) female rats. In addition, the effect of hormone replacement was evaluated in ovariectomized rats with intraperitoneal injection of $17 \beta$-estradiol (E2; $50 \mu \mathrm{g} / \mathrm{kg}) 1 \mathrm{hr}$ before carrageenan treatment (OVX + E2). Results: Ovariectomy enhanced the carrageenan-induced degree of pleural exudation and polymorphonuclear leukocyte migration in rats subjected to carrageenaninduced pleurisy. Lung myeloperoxidase (MPO) activity
\end{abstract}

and lipid peroxidation were significantly increased in estrogens-deprived rats. The iNOS in lung samples was significantly increased by the surgery. The increase of iNOS activity was correlated with a marked enhancement in the production of TNF- $\alpha$ and IL- $1 \beta$. Immunohistochemical analysis for P-selectin and ICAM-I, as well as nitrotyrosine and poly (ADP-ribose) synthetase (PARS) revealed a positive staining in lungs from carrageenantreated rats, which was markedly enhanced in ovariectomized rats when compared to cycling rats, particularly in the estrous phase of the cycle. Estrogen replacement counteracted the effect of surgery on all of the above indicators of lung inflammation, suggesting that in the cycling rat this hormone plays a key role in the increased sensitivity to inflammatory injury observed in the OVX rat.

Conclusion: This study demonstrates that endogenous estrogens production plays an important protective role against carrageenan-induced acute inflammation by decreasing the expression of specific markers of the delayed phase of this well-known model of acute inflammation.

\section{Introduction}

It is well established that gender or physiologic states like pregnancy or menopause have a major influence on the manifestation of several pathologies with a high inflammatory component. These observations led to the theory that female sex hormones, and estrogens in particular, may play a relevant role in immune system control, and therefore in the evolution of these disorders. Several animal models support this view; however, the mechanisms underlying these effects remain poorly understood. A confusing element in the comprehension of the reciprocal influence of estrogens and the immune system in pathologic and physiologic states is linked to the

Address correspondence and reprint requests to: Salvatore Cuzzocrea, PhD Institute of Pharmacology, School of Medicine, University of Messina, Torre Biologica-Policlinico Universitario Via C. Valeria-Gazzi-98100 Messina, Italy. Phone: (39) 090 22 13644; Fax: (39) 090 694951; e-mail: salvator@www.unime.it observation that the hormone may have opposite activities. For instance, it is well known that the estrogen-dependent maturation of follicles is an inflammatory-like reaction $(1,2)$. Similarly, the incidence of autoimmune disorders like systemic lupus erythematosus (SLE) is much higher in women than in men, and menopause decreases its symptomatology (3). Finally, elevated levels of estrogens are associated with several markers of systemic inflammation (4).

On the other hand, several other lines of evidence support the concept that estrogens have antiinflammatory action. The incidence of rheumatoid arthritis (RA) is lower in fertile women than in men (5). The same is true for cardiovascular insults, possibly because women have a lower incidence of chronic inflammation-related atheromatous lesions (6). Multiple sclerosis undergoes remission during pregnancy and is exacerbated in the postpartum period (7). During menopause, hormone replacement 
therapy users compared to nonusers show a delayed manifestation of neurodegenerative diseases with inflammatory components like Alzheimer's disease (8) have a reduced risk of cardiovascular events (9) and show a slower progression of osteoporosis (10) possibly because estrogens, by suppressing inflammatory cytokine production, promote osteoclastogenesis and bone resorption (11). In several animal models, estrogens display antiinflammatory activity: rat adjuvant-induced arthritis (12), endotoxin-induced uveitis (13), vascular inflammatory reaction (14), and experimental encephalomyelitis (15). The mechanism by which the systemic administration of estradiol results in an anti-inflammatory activity may be due to the hormone-dependent blockade of cytokine (interleukin 1 [IL-1], IL-6, tumor necrosis factor- $\alpha$ $[\mathrm{TNF}-\alpha]$ ) production. Estrogens might also inhibit macrophage infiltration in the damaged tissues. Macrophages express both the described intracellular estrogen receptors (ER $\alpha$ and ER $\beta$ ) (16) and their exposure to low concentrations of estradiol results in decreased production of inflammatory agents such as IL- $1 \alpha$ and IL-1 $\beta$ (16) or enzymes facilitating their migration like metalloproteases (17). In specific organs, then, estradiol may contribute to the containment of the inflammatory production by decreasing the synthesis of inducible nitric oxide synthetase (iNOS), PGE2 $\alpha$, (e.g., in the brain microglia) (17), PAI-1 (liver) (18), or others not yet described.

In view of the increasing number of women chronically treated with estrogen for oral contraception or replacement therapy, it is of great importance to investigate on the activity of this sex hormone in inflammation.

The aim of the present study was to investigate the role of endogenous estrogens in a well-known murine model of acute inflammation like carrageenaninduced pleurisy (19). It is well known that the early phase of the carrageenan-induced pleurisy is related to the production of histamine, leukotrienes, platelet-activating factors, and possibly cyclooxygenase products. The delayed phase is linked to neutrophil infiltration and neutrophil-derived free radicals and oxidants, such as hydrogen peroxide, superoxide, and hydroxyl radicals, as well as to release of other neutrophil-derived mediators (20-24) that cause tissue necrosis. We here show that decreased levels of circulating sex hormones induced by ovariectomy have significant repercussions in the delayed phase of the rat inflammatory response to carrageenan injection by significantly increasing the expression of selected inflammatory markers. The observation that estrogen replacement counteracts the effect of ovariectomy leads us to propose that this hormone might have anti-inflammatory properties. These observations are relevant to the understanding on the role of this sex hormone in nonreproductive tissues.

\section{Materials and Methods Reagents}

Primary anti-nitrotyrosine antiserum was from Upstate Biotech (DBA, Milan, Italy). All other reagents and compounds used were obtained from Sigma Chemical Company (Milan, Italy).

\section{Animals}

Female Sprague-Dawley rats (300-350 g; Charles River, Milan, Italy) were housed in a controlled environment and provided with standard rodent chow and water. Animal care was in compliance with Italian regulations on protection of animals used for experimental and other scientific purposes (D.M. 116192) as well as with the EEC regulations (O.J. of E.C. L 358/1 12/18/1986).

\section{Ovariectomy}

Surgery was performed under halothane $(2 \%)$ anesthesia followed by nitrous oxygen $/ \mathrm{O}_{2}$ anesthesia for about $18 \mathrm{~min}$. Ovariectomy was done through a single dorsal midline cutaneous incision followed by bilateral muscle incisions.

\section{Carrageenan-Induced Pleurisy}

Rats were anaesthetized with isoflurane and submitted to a skin incision at the level of the left sixth intercostal space. The underlying muscle was dissected and saline $(0.2 \mathrm{ml})$ or saline containing $1 \%$ $\lambda$-carrageenan $(0.2 \mathrm{ml})$ were injected into the pleural cavity. The skin incision was closed with a suture and the animals were allowed to recover. Four hours after the injection of carrageenan, the animals were killed by inhalation of $\mathrm{CO}_{2}$. The chest was carefully opened and the pleural cavity rinsed with $2 \mathrm{ml}$ of saline solution containing heparin $\left(5 \mathrm{U} \cdot \mathrm{ml}^{-1}\right)$ and indomethacin $\left(10 \mu \mathrm{g} \cdot \mathrm{ml}^{-1}\right)$. The exudate and washing solution were removed by aspiration and the total volume was measured. Any exudate contaminated with blood was discarded. The amount of exudate was calculated by subtracting the volume injected $(2 \mathrm{ml})$ from the total volume recovered. The leukocytes in the exudate were suspended in phosphate-buffered saline (PBS) and counted with an optical microscope in a Burker's chamber after vital Trypan blue staining. The effects of carrageenan (or vehicle) injury were observed in the following groups of rats: ovariectomized (OVX), cycling in the estrogenic phase (N-OVX) and ovariectomized treated with $17 \beta$-estradiol (E2; $50 \mu \mathrm{g} / \mathrm{kg}$; intraperitoneally) $1 \mathrm{hr}$ before the carrageenan challenge $(\mathrm{OVX}+\mathrm{E2})$. Each experimental group was composed of 10 rats.

\section{Measurement of Circulating Estrogens by Allen-Doisy Bioassay and Radioimmunoassay}

The state of proliferation and keratinization of the vaginal epithelium is known to closely reflect the extent of circulating estrogens (25). Vaginal smears 


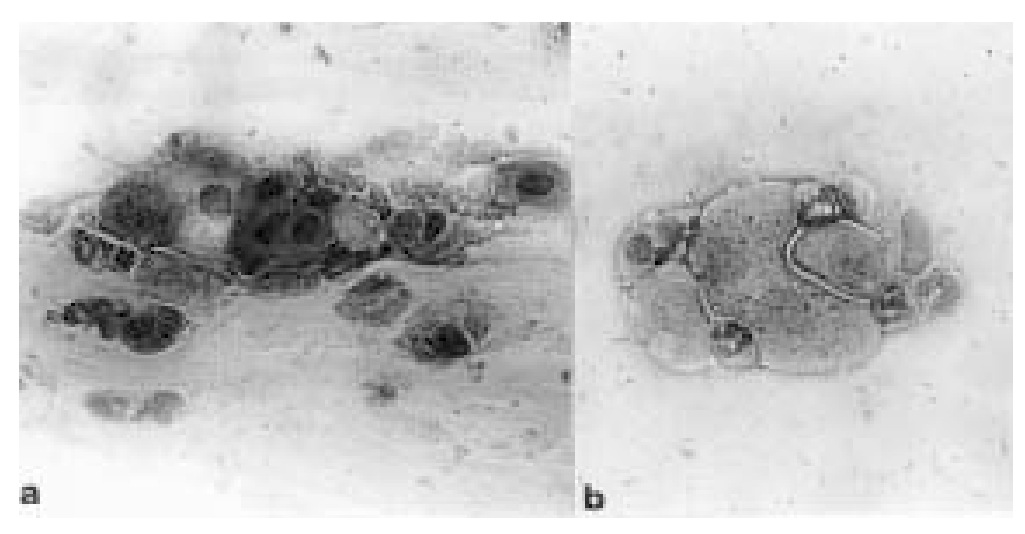

Fig. 1. Allen-Doisy assay. Vaginal smears with the presence of cornfield cells (A) with large squamous epithelial cells or with a few leukocytes and nucleated epithelial cells indicate that the rats are in the estrous or metaestrus, respectively, phase of the cycle. Only rats in estrus were used in the $\mathrm{N}-\mathrm{OVX}$ group. Original magnification $\times 145$. were therefore performed to assess the phase of the estral cycle in intact rats. Rats in which the test showed only cornified cells were selected for the experiment (Fig.1). Fourteen days after ovariectomy only leukocytes were present in the vaginal smears, proving the depletion of circulating estrogens. In addition, plasma estradiol levels were measured by using a radioimmunoassay (RIA) (Inalco, Milan, Italy). The crossreactivity of the estradiol antiserum with corticosterone was less than $0.017 \%$. The limit of sensitivity of the assay was $12 \mathrm{pg} / \mathrm{ml}$ of plasma. The intra- and interassay coefficients of variation were $6 \%$ and $7 \%$, respectively. In cycling rats, plasma levels measured were $29 \pm 0.33 \mathrm{pg} / \mathrm{ml}$, and in 3 weeks OVX rats, estradiol was below levels of detection of the method.

\section{Measurement of Nitrite/Nitrate}

Nitrite production, an indicator of NO synthesis, was measured in the exudate as previously described (2). Briefly, the nitrate in the exudate was first reduced to nitrite by incubation with nitrate reductase $\left(670 \mathrm{mU} \cdot \mathrm{ml}^{-1}\right)$ and NADPH $(160 \mu \mathrm{M})$ at room temperature for $3 \mathrm{hr}$. The nitrite concentration in the samples was then measured by the Griess reaction, by adding $100 \mu \mathrm{l}$ of Griess reagent $(0.1 \%$ naphthylethylenediamide dihydrochloride in $\mathrm{H}_{2} \mathrm{O}$ and $1 \%$ sulphanilamide in $5 \%$ concentrated $\mathrm{H}_{2} \mathrm{PO}_{4}$; vol $1: 1)$ to $100-\mu l$ samples. The optical density at $550 \mathrm{~nm}\left(O D_{550}\right)$ was measured using enzyme-linked immunosorbent assay (ELISA) microplate reader (SLT Labinstruments, Salzburg, Austria). Nitrite concentration was calculated by comparison with $O D_{550}$ of standard solutions in DMEM medium.

\section{Histologic Examination}

Lung biopsies were taken at $4 \mathrm{hr}$ after injection of carrageenan. The biopsies were fixed for 1 week in buffered formaldehyde solution (10\% in PBS) at room temperature, dehydrated by graded ethanol, and embedded in Paraplast (Sherwood Medical, Mahwah, NJ, USA). Tissue sections (thickness $7 \mu \mathrm{m}$ ) were deparaffinized with xylene, stained with trichromic Van Gieson, and studied using light microscopy (Dialux 22 Leitz).

\section{Immunofluorescence Localization of ICAM-1, $P$-Selectin, Nitrotyrosine, and PARS}

Indirect immunofluorescence staining was performed on 7- $\mu \mathrm{m}$ thick sections of unfixed rat lung. Sections were cut in with a Slee and London cryostat at $-30^{\circ} \mathrm{C}$, transferred onto clean glass slides, and dried overnight at room temperature. Sections were permeabilized with acetone at $-20^{\circ} \mathrm{C}$ for $10 \mathrm{~min}$ and rehydrated in PBS (150 mM NaCl, $20 \mathrm{MM}$ sodium phosphate, $\mathrm{pH}$ 7.2) at room temperature for $45 \mathrm{~min}$. Sections were incubated overnight with either rabbit anti-human polyclonal antibody directed at P-Selectin (CD62P), which reacts with rat and mouse anti-rat antibody directed at ICAM-1 (CD54) (1:500 in PBS, v/v) (DBA, Milan, Italy); with anti-nitrotyrosine rabbit polyclonal antibody (1:500 in PBS, v/v); or with anti-poly (ADP-Ribose) goat polyclonal antibody rat (1:500 in PBS, v/v). Sections were washed with PBS and incubated with secondary antibody (TRITCconjugated anti-rabbit and with FITC-conjugated anti-mouse (Jackson, West Grove, PA, USA) or with TRITC-conjugated anti-goat antibody (1:80 in PBS, $\mathrm{v} / \mathrm{v}$ ) for $2 \mathrm{hr}$ at room temperature. Sections were washed as before, mounted with $\mathbf{9 0 \%}$ glycerol in PBS, and observed with a Nikon RCM8000 confocal microscope equipped with a $40 \times$ oil objective.

To confirm that the immunoreaction for the nitrotyrosine was specific, some sections were also incubated with the primary antibody (antinitrotyrosine) in the presence of excess nitrotyrosine (10 $\mathrm{mM})$ to verify the binding specificity. To verify the binding specificity for PARS, some sections were also incubated with only the primary (no secondary) antibody or with only the secondary(no primary) antibody. To verify the binding specificity for ICAM-1 or P-selectin, some sections were also incubated with only the primary(no secondary) antibody or with only the secondary (no primary)antibody. In these situations, no positive staining was found in the sections indicating that the immunoreaction was positive in all the experiments carried out.

Immunofluorescence photographs $(n=5)$ were assessed by densitometry. The assay was carried out by using Optilab Graftek software on a Macintosh computer as previously described (26). 


\section{Myeloperoxidase Activity}

Myeloperoxidase (MPO) activity, an indicator of polymorphonuclear leukocyte (PMN) accumulation, was determined as previously described (27). Four hours following the intrapleural injection of carrageenan, lung tissues were obtained and weighed. Each piece of tissue was homogenized in a solution containing $0.5 \%$ hexa-decyl-trimethyl-ammonium bromide dissolved in 10-mM potassium phosphate buffer $(\mathrm{pH} \mathrm{7})$ and centrifuged for $30 \mathrm{~min}$ at $20,000 \mathrm{~g}$ at $4^{\circ} \mathrm{C}$. An aliquot of the supernatant was then allowed to react with a solution of tetra-methyl-benzidine (1.6 mM) and $0.1 \mathrm{mM}$ of $\mathrm{H}_{2} \mathrm{O}_{2}$. The rate of change in absorbance was measured spectrophotometrically at $650 \mathrm{~nm}$. MPO activity was defined as the quantity of enzyme degrading $1 \mu \mathrm{mol}$ of peroxide $\min ^{-1}$ at $37^{\circ} \mathrm{C}$ and was expressed in milliunits per gram weight of wet tissue.

\section{Malondialdehyde Measurement}

Malondialdehyde (MDA) levels in the lung tissue were determined as an indicator of lipid peroxidation (28). Lung tissues, collected at the specified time, were homogenized in $1.15 \% \mathrm{KCl}$ solution. An aliquot $(100 \mu \mathrm{l})$ of the homogenate was added to a reaction mixture containing $200 \mu \mathrm{l}$ of $8.1 \%$ SDS, $1500 \mu \mathrm{l}$ of $20 \%$ acetic acid (pH 3.5), $1500 \mu$ l of $0.8 \%$ thiobarbituric acid, and $700 \mu \mathrm{l}$ distilled water. Samples were then boiled for $1 \mathrm{hr}$ at $95^{\circ} \mathrm{C}$ and centrifuged at $3000 \mathrm{~g}$ for $10 \mathrm{~min}$. The absorbance of the supernatant was measured by spectrophotometry at $650 \mathrm{~nm}$.

\section{Determination of Nitric Oxide Synthase Activity}

The calcium-independent conversion of L-arginine to L-citrulline in the homogenates of lungs (obtained $4 \mathrm{hr}$ after carrageenan treatment in the presence or the absence of E2) served as an indicator of iNOS activity (29). Cells were scraped into a homogenization buffer composed of $50 \mathrm{mM}$ Tris $\mathrm{HCl}, 0.1 \mathrm{mM}$ EDTA, and $1 \mathrm{mM}$ phenylmethylsulphonyl fluoride (pH 7.4) and homogenized in the buffer on ice using a tissue homogenizer. Conversion of $\left[{ }^{3} \mathrm{H}\right]$-L-arginine to $\left[{ }^{3} \mathrm{H}\right]-\mathrm{L}$-citrulline was measured in the homogenates as previously described (30). Briefly, homogenates $(30 \mu \mathrm{l})$ were incubated in the presence of $\left[{ }^{3} \mathrm{H}\right]$-L-arginine (10 $\mu \mathrm{M}, 5 \mathrm{kBq}$ per tube), NADPH (1 $\mathrm{mM})$, calmodulin (30 $\mathrm{nM})$, tetrahydrobiopterin (5 $\mu \mathrm{M})$, and EGTA $(2 \mathrm{mM})$ for $20 \mathrm{~min}$ at $22^{\circ} \mathrm{C}$. Reactions were stopped by dilution with $0.5 \mathrm{ml}$ of ice-cold HEPES buffer ( $\mathrm{pH}$ 5.5) containing EGTA (2 $\mathrm{mM})$ and EDTA (2 $\mathrm{mM})$. Reaction mixtures were applied to Dowex 50W ( $\mathrm{Na}^{+}$form) columns and the eluted $\left[{ }^{3} \mathrm{H}\right]-\mathrm{L}$-citrulline activity was measured by a Beckman scintillation counter.

\section{Measurement of Cytokines}

TNF- $\alpha$ and IL- $1 \beta$ levels were evaluated in exudate at $4 \mathrm{hr}$ after the induction of pleurisy. The assay was carried out by using a colorimetric, commercial kit (Calbiochem-Novabiochem Corporation, Milan, Italy).

\section{Statistical Analysis}

All values in the figures and text are expressed as mean \pm standard error (SEM) of the mean of $n$ observations. For the in vivo studies, $n$ represents the number of animals studied. In the experiments involving histology or immunohistochemistry, the figures shown are representative of at least three experiments performed on different experimental days. The results were analyzed by one-way ANOVA followed by a Bonferroni post hoc test for multiple comparisons. A $p$-value less than 0.05 was considered significant.

\section{Results \\ Endogenous Estrogen Production Protects Against Carrageenan-Induced Pleurisy}

All carrageenan-injected (N-OVX) rats developed acute pleurisy, producing $1.23 \pm 0.06 \mathrm{ml}$ of turbid exudate (Fig. 2A). Trypan blue stain revealed $66 \pm$ $1.3 \times 10^{6} \mathrm{PMNs}$ per rat in comparison to salinetreated rats $\left(2.2 \pm 0.9 \times 10^{6}\right.$ per rat) (Fig. $\left.2 \mathrm{~B}\right)$. However, the effect of carrageenan treatment was significantly reduced in cycling versus OVX rats. Similarly, $\mathrm{NO}_{\mathrm{x}}$ levels were also significantly $(p<$ 0.01) increased in the exudate from carrageenanchallenged $\mathrm{N}-\mathrm{OVX}$ rats $(46 \pm 2.8$ nmoles per rat versus $4.4 \pm 1.2$ nmoles per saline rat) (Fig. $3 \mathrm{~A}$ ). In the lungs obtained from $\mathrm{N}-\mathrm{OVX}$ rats subjected to carrageenan-induced pleurisy, a significant increase of iNOS activity was also detected at $4 \mathrm{hr}$ (129 \pm $5 \mathrm{fmol} / \mathrm{mg} / \mathrm{min}$ ) (Fig. 3B). Animals treated with saline demonstrated no abnormalities in the pleural cavity or fluid. The degree of pleural exudation, polymorphonuclear migration, and NO production were significantly enhanced in OVX rats when compared with cycling rats (Figs. 2 and 3). Ovariectomy did not cause significant changes in these parameters in saline-treated rats (Figs. 2 and 3). E2 treatment significantly reverted the effect of OVX and significantly reduced the degree of pleural exudation, polymorphonuclear migration, and NO formation in carrageenan-treated rats (Figs. 2 and 3). At $4 \mathrm{hr}$ after carrageenan administration, lungs were examined for MPO activity, indicative of neutrophil infiltration and for MDA, to estimate lipid peroxidation. After carrageenan injection, MPO activity and MDA levels (58 $\pm 2 \mathrm{mU} / 100 \mathrm{mg}$ wet tissue, $218 \pm 9 \mu \mathrm{M} / 100 \mathrm{mg}$ wet tissue, respectively) in the lungs of cycling $(\mathrm{N}-\mathrm{OVX})$ rats were significantly higher than in saline-treated rats $(19 \pm 4 \mathrm{mU} / 100 \mathrm{mg}$ wet tissue, $175 \pm 6 \mu \mathrm{M} / 100 \mathrm{mg}$ wet tissue, respectively) (Figs. $4 \mathrm{~A}$ and $4 \mathrm{~B}$ ). Ovariectomy significantly augmented the carrageenan-induced MPO activity and MDA levels (to $99 \pm 8 \mathrm{mU} / 100 \mathrm{mg}$ wet tissue and $301 \pm 6 \mu \mathrm{M} / 100 \mathrm{mg}$ wet tissue, respectively) (Figs. 4A and 4B). E2 treatment significantly reverted the effects of OVX and significantly reduced MPO activity and malondialdehyde levels (Figs. 4A and 4B). 

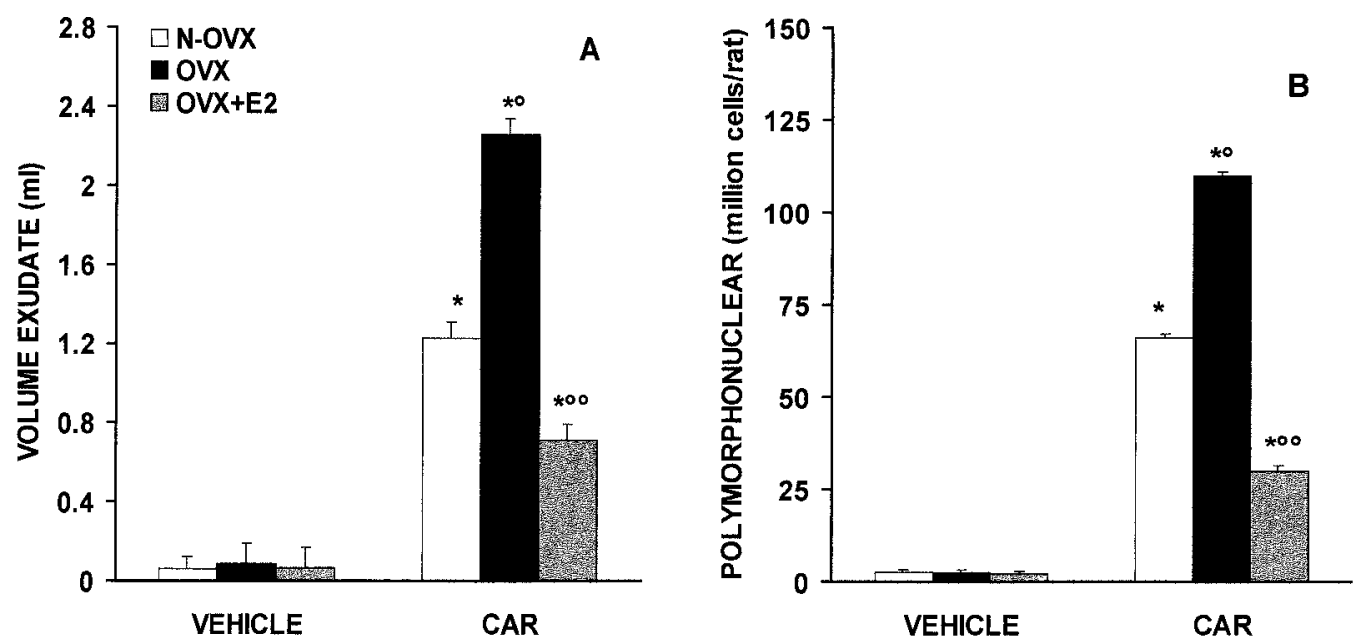

Fig. 2. Effect of endogenous estrogen on carrageenan-induced inflammation. Volume exudate (A) and polymorphonuclear accumulation (B) in pleural cavity at $4 \mathrm{hr}$ after carrageenan injection. Estrogen depletion significantly increased pleural exudation and leukocyte migration. Data are presented as mean \pm SEM of 10 rats for each group. ${ }^{*} p<0.01$ versus sham. ${ }^{\circ} p<0.01$ versus carrageenan-treated N-OVX rats. ${ }^{\circ} p<0.01$ versus carrageenan-treated OVX rats.

At $4 \mathrm{hr}$ after carrageenan injection, staining for ICAM-1 (2.1 $\pm 0.08 \%$ of total tissue area) was found increased along the bronchial epithelium and in vessels from carrageenan-treated N-OVX rats when compared with saline treaded rats (Fig. 5A arrows). Lung tissue section obtained from carrageenantreated N-OVX rats showed positive staining for P-selectin $(2.30 \pm 0.09 \%$ of total tissue area) localized in the bronchial epithelium and in vessels (Fig. 5B arrows). In carrageenan-treated OVX rats, the staining for ICAM-1 $(5.30 \pm 0.1 \%$ of total tissue area) or P-selectin (5.42 $\pm 0.07 \%$ of total tissue area) was visibly and significantly increased (Figs. 5D and 5E) in comparison with the cycling rats. It is important to emphasize that no staining for ICAM-1

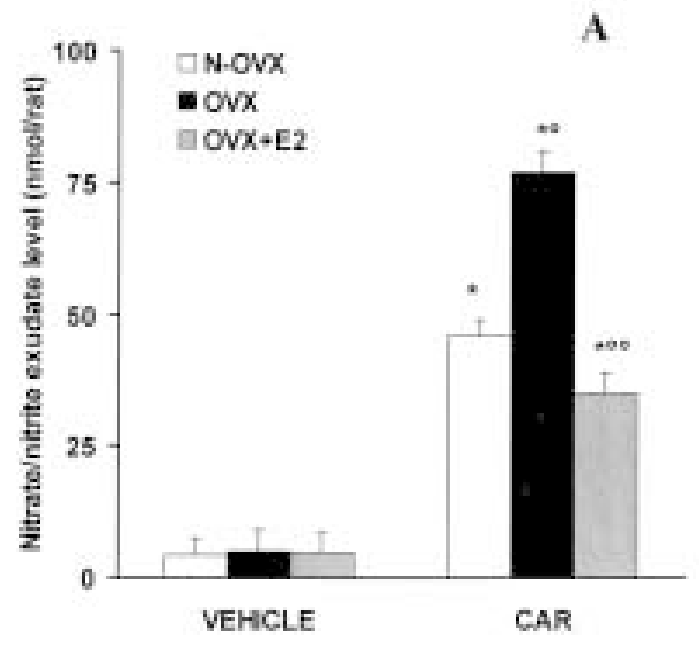

or P-selectin was observed in lungs of saline-treated rats (data not shown). E2 treatment significantly reverted the effects of OVX and significantly reduced the increase of ICAM-1 and P-selectin (data not shown).

After the carrageenan challenge, TNF- $\alpha$ (321 \pm $12.8 \mathrm{pg} / \mathrm{ml}$ versus $10.4 \pm 1.2 \mathrm{pg} / \mathrm{ml} / \mathrm{sham} \mathrm{rat}$ ) and IL- $1 \beta(164 \pm 8.8 \mathrm{pg} / \mathrm{ml}$ versus $12.4 \pm 1.2 \mathrm{pg} / \mathrm{ml} / \mathrm{sham}$ rats) were also significantly $(p<0.01)$ increased in the exudate from $\mathrm{N}-\mathrm{OVX}$ rats in comparison to saline treated rats (Fig. 6). The degree of TNF- $\alpha$ $(534 \pm 21.8 \mathrm{pg} / \mathrm{ml})$ and $\mathrm{IL}-1 \beta(273 \pm 7.8 \mathrm{pg} / \mathrm{ml})$ production was significantly enhanced in OVX rats as compared to cycling rats (Fig. 6). E2 treatment significantly reverted the effects of OVX and significantly

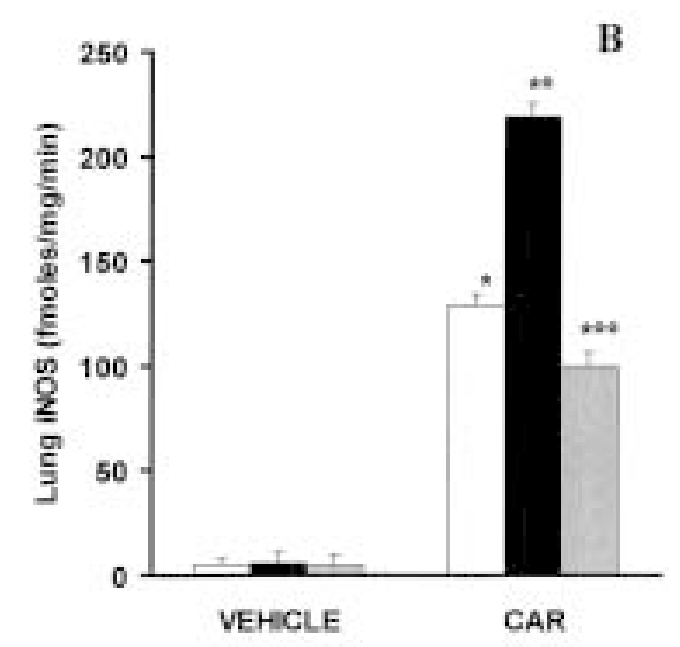

Fig. 3. Effect of endogenous estrogen on NO production. Nitrite and nitrate concentrations in pleural exudate (A) and iNOS activity in lungs (B) at $4 \mathrm{hr}$ after carrageenan administration. iNOS activity in the carrageenan-treated rats was significantly increased versus sham group. Estrogen depletion significantly affect the NO production. Value are presented as mean \pm SEM of 10 rats for each group. ${ }^{*} p<0.01$ versus sham. ${ }^{\circ} p<0.01$ versus carrageenan-treated $\mathrm{N}$-OVX rats. ${ }^{\circ} p<0.01$ versus carrageenan-treated OVX rats. 

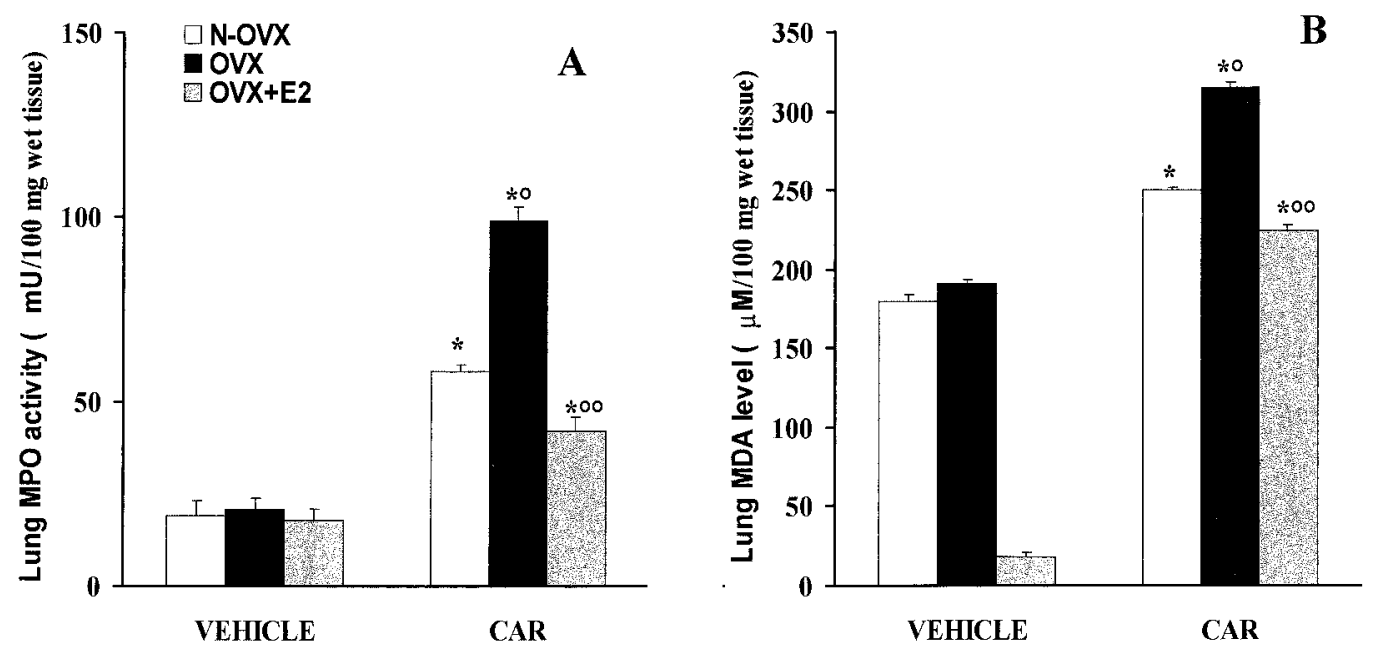

Fig. 4. Effect of endogenous estrogen on polymorphonuclear leukocyte migration and lipid peroxidation. MPO activity (A) and MDA (B) in the lungs of carrageenan-treated rats sacrificed at $4 \mathrm{hr}$. MPO activity and MDA levels were significantly increased in the lungs of the carrageenan-treated rats in comparison to sham-treated rats. Estrogen depletion significantly enhanced the

carrageenan-induced increase in MPO activity and MDA levels. Values are presented as mean \pm SEM of 10 rats for each group. * $p<$ 0.01 versus sham. ${ }^{\circ} p<0.01$ versus carrageenan-treated N-OVX rats. ${ }^{\circ} p<0.01$ versus carrageenan-treated OVX rats.

reduced the increase of TNF- $\alpha$ and IL-1 $\beta$ (Fig. 6). The absence of estrogens did not cause significant changes in these parameters in sham rats (Fig. 6).

At $4 \mathrm{hr}$ following the intrapleural injection of carrageenan, lung sections were analyzed for the presence of nitrotyrosine. Immunohistochemical analysis in lungs from carrageenan-treated OVX rats (Fig. 7D arrows), using a specific anti-nitrotyrosine antiserum, revealed significantly more positive staining (5.50 \pm $0.06 \%$ of total tissue area) than carrageenan-treated rats in cycling $(\mathrm{N}-\mathrm{OVX})$ rats $(2.25 \pm 0.08 \%$ of total tissue area) (Fig. 7A arrows). Immunohistochemical analysis for PARS from lung sections obtained from OVX rats (Fig. 7E arrows) treated with carrageenan also revealed significantly more positive staining for PARS $(4.32 \pm 0.11 \%$ of total tissue area) than in carrageenan-treated cycling (N-OVX) rats $(1.40 \pm$ $0.05 \%$ of total tissue area) (Fig. 7B). Note that there was no staining for either nitrotyrosine or PARS in lungs obtained from saline-treated rats (data not shown). E2 treatment significantly reverted the effects of OVX and significantly reduced the increase of nitrotyrosine and PARS (data not shown).

Histologic examination of lung sections of $\mathrm{N}$ OVX rats treated with carrageenan showed tissue injury as well as inflammatory cells infiltration (Fig. 8B). In contrast, the absence of estrogen production induced a significant increase in the inflammatory cell infiltration as well as a more pronounced lung injury (Fig. 8A). E2 treatment significantly reverted the effects of OVX and significantly reduced the lung injury (data not shown).

\section{Discussion}

The results of the present study suggest that endogenous estrogens are a protective factor against the carrageenan-induced development of acute inflammation. Our findings are in agreement with previous reports from our (31) and other laboratories $(32,33)$, which show that estrogens may inhibit inflammatory responses in which PMN play a key role. The mechanism underlying this effect has not been elucidated. To our knowledge, this is the first investigation to address the molecular mechanism of endogenous estrogens anti-inflammatory activity.

\section{Endogenous Estrogen Protects Against Lung Injury by Controlling Neutrophil Migration}

The most evident finding in the present study was that the ovariectomized rats showed a remarkable increase in the degree of pleural exudate and polymorphonucleate cells migration than cycling animals. Neutrophils play a crucial role in the full manifestation of the inflammatory process and their infiltration into inflamed tissues is essential for the fate of foreign antigens and production of oxidative products leading to tissue injury and remodeling. The extravasation of PMNs into the inflamed tissue involves leukocyte rolling, followed by adherence and transendothelial migration. In this process P-selectin, a member of the selecting family of adhesion molecules, directs the initial phase of these cell migrations, which involves their rolling along the vascular endothelium. This is instrumental to tethering the unstimulated neutrophil to the endothelium, which is activated to express substances such as platelet activating factor promoting adherence $(34,35)$. The P-selectin-mediated adherence of neutrophils to the endothelial cells is not sufficient for the transendothelial migration, a process requiring a more stable intracellular association (36), which is provided by interaction between $\beta 2$ inte- 

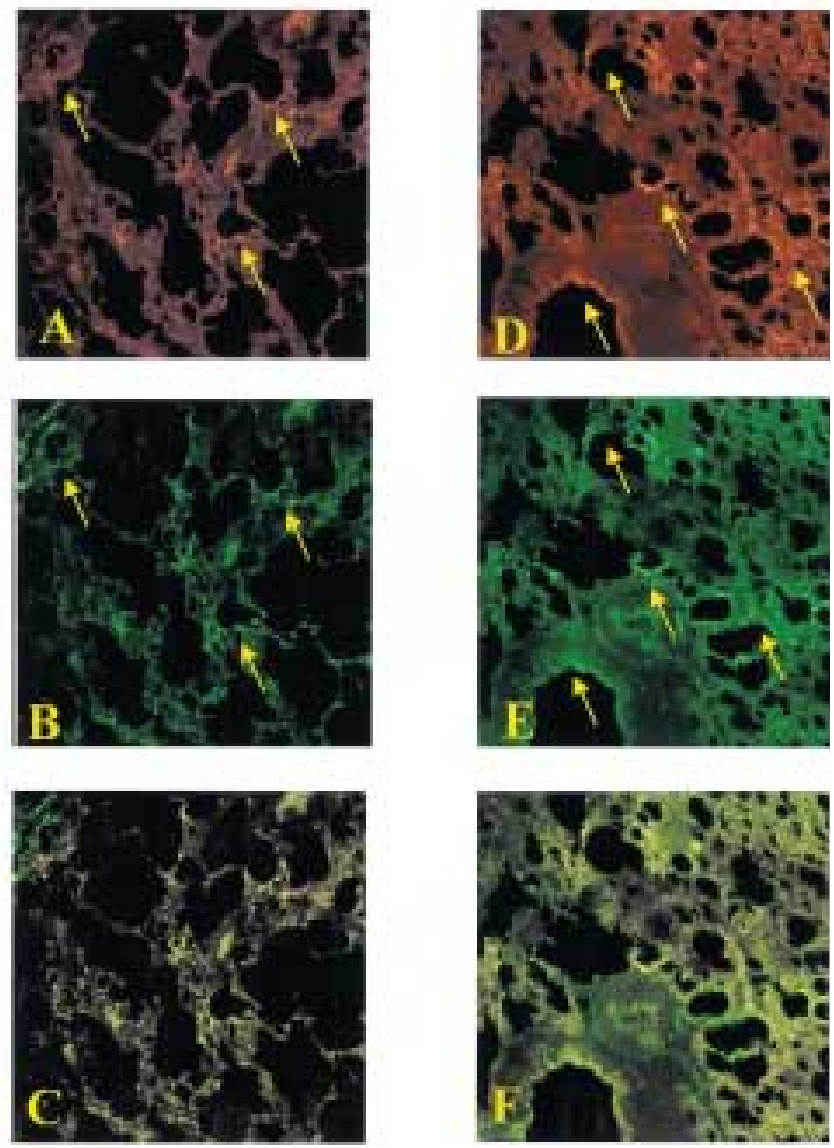

Fig. 5. Immunohistochemical localization of ICAM-1 and P-selectin in the lung. Section obtained from carrageenantreated $\mathrm{N}-\mathrm{OVX}$ rats showed intense positive staining for ICAM-1 (A) and for P-selectin (B) on bronchial epithelium (arrows). The degree of bronchial epithelium staining for ICAM-1 (D) and for P-selectin (E) was markedly increased in tissue section obtained from OVX rats. $\mathbf{C}$ and $\mathbf{F}$ represent the staining combination of panels $\mathrm{A}$ and $\mathrm{B}$ and $\mathrm{D}$ and $\mathrm{E}$, respectively. Original magnification $\times 145$. Figure is representative of at least three experiments performed on different experimental days.

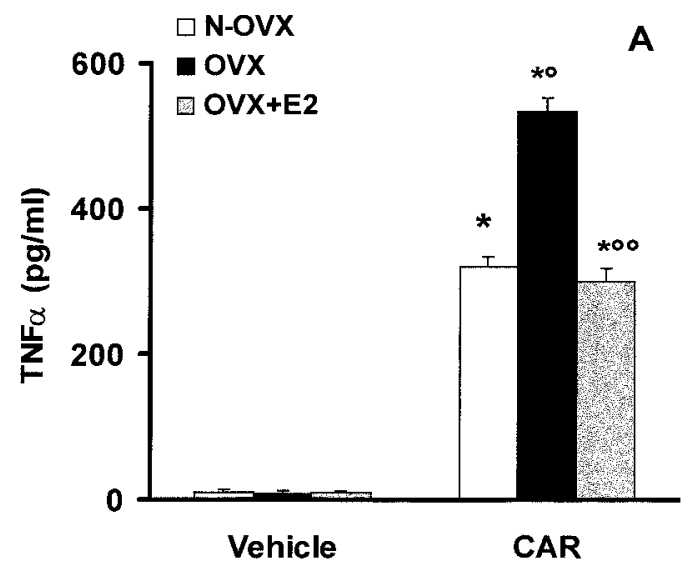

grins (i.e., CD11/CD18) on the PMN surface and intracellular adhesion molecule 1 (ICAM-1) on the endothelial cells surface $(37,38)$. Our study provides a potential mechanism by which endogenous estrogens contribute to the regulation of neutrophil infiltration by showing that the lack of endogenous estrogens results in higher production of P-selectin and ICAM- 1 in tissues exposed to an inflammatory agent like carrageenan. This is in line with emerging experimental evidence linking estrogen activity with cell adhesion molecules. It has been demonstrated in fact that in cycling women there is a maximal decrease in P-selectin levels during the luteal phase. In addition, a single intramuscular injection of $17 \beta$-estradiol significantly lowered soluble P-selectin levels in healthy male volunteers (39).

\section{Ovariectomy Results in Higher Production of Oxidative Products in Carrageenan-Induced Pleurisy}

Previous studies have shown the important role played by infiltrating inflammatory cells in the development of the pathologic features of pleurisy $(21,40)$. Several hypotheses may explain this phenomenon. Although NO itself is a weak oxidant, biochemical studies have shown that NO rapidly interacts with superoxide anion to yield peroxynitrite and its conjugate acid, peroxynitrous acid, which then decomposes to form highly reactive oxidant species, such as hydroxyl and nitrogen dioxide.

Using nitrotyrosine immunohistochemistry, this study confirms the production of peroxynitrite in the lung of rats subjected to carrageenan-induced pleurisy. Nitrotyrosine formation, along with its detection by immunostaining, was initially proposed as a relatively specific marker for the detection of the endogenous formation "footprint" of peroxynitrite (41). There is, however, recent evidence that certain other reactions can also induce tyrosine nitration (e.g., the reaction of nitrite with hypochlorous acid

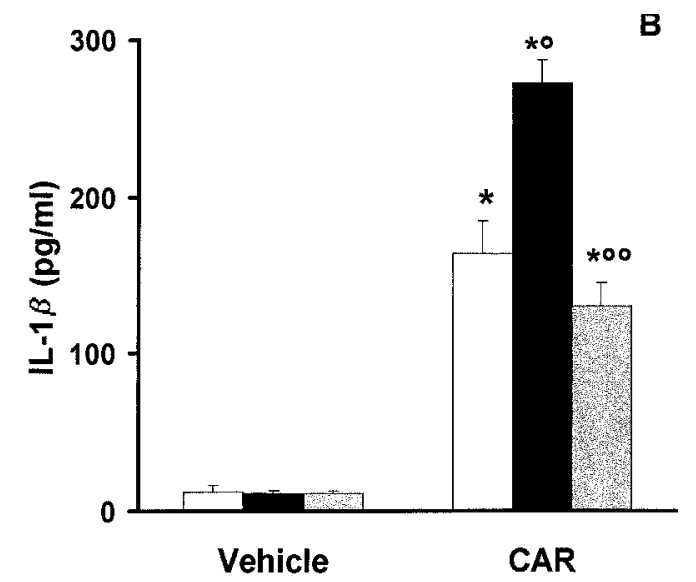

Fig. 6. Effect of endogenous estrogen on cytokines production. TNF- $\alpha$ (A) and IL-1 $\beta$ (B) levels in pleural exudate at 4 hr after carrageenan administration. Cytokine production in the carrageenan-treated N-OVX rats was significantly increased versus shamtreated group. Estrogen depletion significantly affect the cytokines production. Value are presented as mean \pm SEM of 10 rats for each group. ${ }^{*} p<0.01$ versus sham. ${ }^{\circ} p<0.01$ versus carrageenan-treated $\mathrm{N}-\mathrm{OVX}$ rats. ${ }^{\circ} p<0.01$ versus carrageenan-treated OVX rats. 

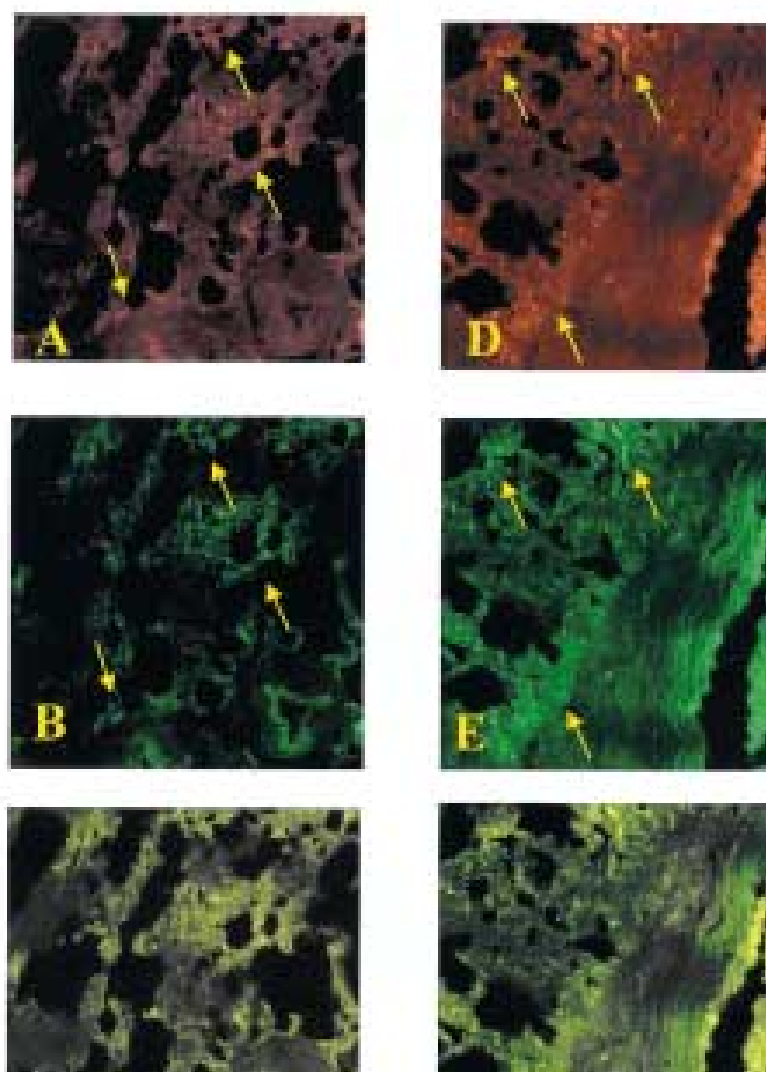

Fig. 7. Immunohistochemical localization for nitrotytosine and for PARS in the lung. Immunohistochemistry for nitrotyrosine (A) and for PARS (B) show positive staining along the vessels (big arrows) and in the bronchial epithelium (small arrows) from a carrageenan-treated N-OVX rats. The intensity of the positive staining for nitrotyrosine (D) and for PARS (E) was markedly increased in tissue section obtained from carrageenan-treated OVX rats. $\mathrm{C}$ and $\mathrm{F}$ represent the staining combination of panel A and B, and D and E, respectively. Original magnification $\times 145$. Figure is representative of at least three experiments performed on different experimental days.

and the reaction of myeloperoxidase with hydrogen peroxide can lead to the formation of nitrotyrosine) (42). Increased nitrotyrosine staining is, therefore, considered an indication of "increased nitrosative stress" rather than a specific marker of the generation of peroxynitrite.

The more pronounced nitrotyrosine staining may be also due to increased production of NO, as demonstrated by the measurement of lung iNOS activity.

Both superoxide and peroxynitrite, directly or via reactive intermediates, may induce cytotoxicity via a number of mechanisms including tyrosine nitration, lipid peroxidation, DNA strand breaks, and the consequent activation of poly-ADP ribose synthase (43-45). Furthermore, nitrogen-centered oxidants may also degrade the iron-sulphur clusters of mammalian mitochondrial NADH-coenzyme

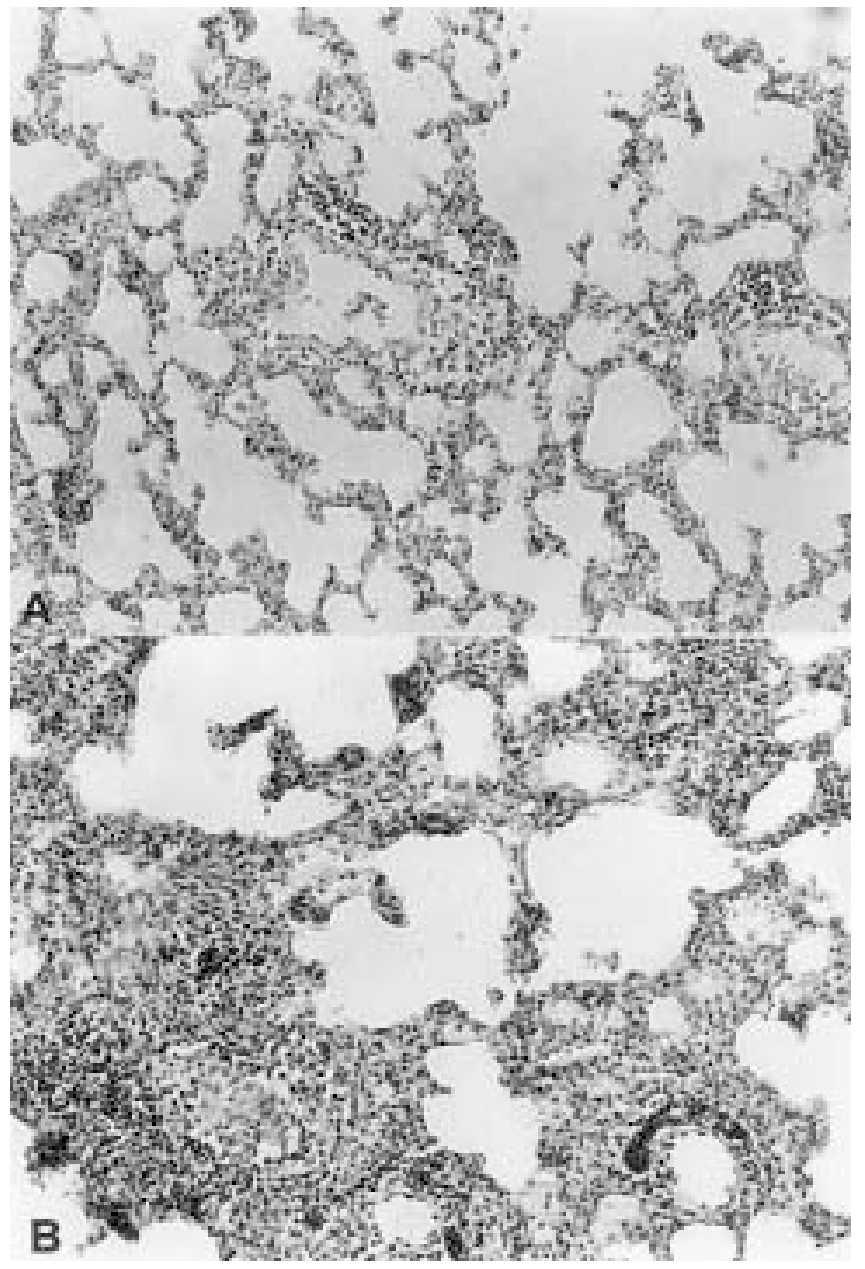

Fig. 8. Effect of endogenous estrogen on lung injury. The lung section from a carrageenan-treated N-OVX rat demonstrates inflammatory cells infiltration (A). The lung section from a carrageenan-treated OVX rat demonstrates a marked increased in cellular infiltration (B). Original magnification $\times 125$. Figure is representative of at least three experiments performed on different experimental days.

$\mathrm{Q}$ reductase, succinate dehydrogenase, aconitase, and ATPase. As a consequence, intracellular iron homoeostasis may be disrupted, providing a catalyst for further generation of deleterious oxygen species from neutrophils $(46,47)$. This study confirms previous reports showing that estradiol down-regulates inducible nitric oxide synthase in rat smooth muscle cells in culture (48), in human macrophages and rat microglia (Vegeto et al., submitted) (49).

\section{Endogenous Estrogens Oppose the Production of Inflammatory Cytokines}

TNF- $\alpha$ and selected cytokines are present in inflamed tissues and their concentration increases in plasma during inflammation. Direct evidence of the role of these compounds in the pathogenesis of experimental pleurisy and other models was obtained by blocking their activity and showing a delay in the onset of the 
pleurisy, suppressing the inflammatory reaction and limiting the lung necrosis ensuing the inflammatory process. Recent studies show that estrogens regulate the production of inflammatory cytokines (IL-1, IL-6, TNF- $\alpha$ ) in bone (18), monocytes and macrophages $(50,51)$, bovine chondrocytes (52). and astroglia (53). In accordance with these findings, we observed that ovariectomy causes a significant increase in carrageenan-induced production of TNF- $\alpha$ and IL- $1 \beta$.

\section{Concluding Remarks}

To our knowledge, this is the first demonstration that ovariectomy results in lowered protection against inflammatory lung injury. In spite of the fact that several reports have provided evidence for a mechanistic interaction between sex hormones synthesized in the ovaries (estrogens in particular) and the molecules involved in the inflammatory reaction, our in vivo study clearly shows that the physiologic concentration of hormones present in cycling rat is sufficient to significantly lower the inflammatory response observed in gonadectomized rats. The finding that estrogen replacement reverts the effect of ovariectomy strongly supports the view of a main protective effect of estradiol at least in this model of acute inflammation.

Our study therefore provides a biochemical support to the concept of a decreased resistance to the manifestation of immune diseases in postmenopausal women based on anedoctal and epidemiologic evidence $(54,55)$. Considering the growing interest in the pharmacologic use of natural and synthetic estrogens, our findings indicate the necessity of a more systematic evaluation of estrogens in inflammatory pathologies.

\section{References}

1. Espey L. (1980) Ovulation as an inflammatory process-a hypothesis. Biol. Reprod. 22: 73-106.

2. Garcia-Velasco JA, Arici A. (1999) Chemokines and human reproduction. Fertil. Steril. 71: 983-993.

3. Lahita RG. (1999) The role of sex hormones in systemic lupus erythematosus. Curr. Opin. Rheumatol. 11: 352-356.

4. Cid MC, Kleinman HK, Grant DS, Schnaper HW, Fauci AS, Hoffman GS. (1994) Estradiol enhances leukocyte binding to tumor necrosis factor (TNF)-stimulated endothelial cells via an increase in TNF-induced adhesion E-selectin, intercellular adhesion molecule type 1 , and vascular cell adhesion molecule type 1. J. Clin. Invest. 93: 17-25.

5. Kay CR, Wingrave SJ. (1983) Oral contraceptives and rheumatoid arthritis. Lancet 25: 1437-1444.

6. Cushman M, Meilahn EN, Psaty BM, Kuller LH, Dobs AS, Tracy RP. (1999) Hormone replacement therapy, inflammation, and hemostasis in elderly women. Arterioscler. Thromb. Vasc. Biol. 19: 893-899.

7. Confacreux C, Huchinson M, Hours MM, Corinovis-Tourniaire P, Moreau T. (1998) Rate of pregnancy-related relapse in multiple sclerosis. Pregnancy in Multiple Sclerosis group. N. Engl. J. Med. 339: 285-291.

8. Honjo H, Tanaka K, Kashiwagi T, Urabe M, Okada H, Hayashi M, Hayashi K. (1995) Senile dementia-Alzheimer's type and estrogen. Hormone Metab. Res. 27: 204-207.
9. Nathan L, Chaudhuri G. (1997) Estrogen and atherosclerosis. Annu. Rev. Pharmacol. Toxicol. 37: 477-515.

10. Horowits MC. (1993) Cytokines and estrogen in bone: antiosteoporotic effects. Science 260: 626-627.

11. Sunyer T, Lewis J, Collin-Osbody P, Osbody P. (1999) Estrogen's bone protective effects may involve differential IL-1 receptor regulation in human osteoclast-like cells J. Clin. Invest. 103: 1409-1418.

12. Badger AM, Blake SM, Dodds RA, et al. (1999) Idoxifene, a Novel Selective Estrogen Receptor Modulator, Is Effective in a Rat Model of Adjuvant-Induced Arthritis. J. Pharmacol. Exp. Ther. 291: 1380-1386.

13. Miyamoto N, Mandai M, Suzuma I, Suzuma K, Kobayashi K, Honda Y. (1999) Estrogen protects against cellular infiltration by reducing the expressions of E-selectin and IL-6 in endotoxin-induced uveitis. J. Immunol. 163: 374-379.

14. Rhodin J, Thomas T, Bryant M, Sutton ET. (2000) Animal model of Alzheimer-like vascular pathology and inflammatory reaction. Ann. N.Y. Acad. Sci. 903: 345-352.

15. Offner H, Adlard K, Zamora A, Vandenbark AA. (2000) Estrogen potentiates treatment with T-cell receptor protein of female mice with experimental encephalomyelitis. J. Clin. Invest. 105: 1465-1472.

16. Vegeto E, Pollio G, Pellicciari C, Maggi A. (1999) Estrogen and progesterone induction of survival of monoblastoid cells undergoing TNF-alpha-induced apoptosis. FASEB J. 13: 793-803.

17. Vegeto E, Bonincontro C, Brusadelli A, et al. (2001) Estrogen prevents lipopolysaccharide-induced inflammatory response in microglia. J. Neurosci. 21: 1809-1818.

18. Angele MK, Knoferl MW, Schwacha MG, et al. (1999) Sex steroids regulate pro- and anti-inflammatory cytokine release by macrophages after trauma-hemorrhage. Am. J. Physiol. 277: C35-C42.

19. Cuzzocrea S, Santagati S, Sautebin L, Mazzon E, Calabrò G, Serraino I, Caputi AP, Maggi A. (2000) 17beta-estradiol antiinflammatory activity in carrageenan-induced pleurisy. Endocrinology 141: 1455-1463.

20. Vane J, Botting R. (1987) Inflammation and the mechanism of action of antiinflammatory drugs. FASEB J. 1: 89-95.

21. Cuzzocrea S, Zingarelli B, Costantino G, Caputi AP. (1999) Beneficial effects of $\mathrm{Mn}(\mathrm{III})$ tetrakis (4-benzoic acid) porphyrin (MnTBAP), a superoxide dismutase mimetic, in carrageenan-induced pleurisy. Free Radic. Biol. Med. 23: 25-32.

22. Oh-Ishi S, Hayashi I, Hayashi M, Yamaki K, Utsunomiya I. (1989) Pharmacological demonstration of inflammatory mediators using experimental inflammatory models: rat pleurisy induced by carrageenin and phorbol myristate acetate. Dermatologica 179: 68-74.

23. Salvemini $D$, Wang ZQ, Wyatt $P$, et al. (1996) Nitric oxide: a key mediator in the early and late phase of carrageenaninduced rat paw inflammation. Br. J. Pharmacol. 118: 829-835.

24. Allen E, Doisy EA. (1983) An ovarian hormone. Preliminary report on its localization, extraction and partial purification, and action in test animals. JAMA 250: 2681.

25. Kahnt LC, Doisy EA. (1928) The vaginal smear method of assay of the ovarian hormone. Endocrinology 12: 760-768.

26. Cuzzocrea S, Misko TP, Costantino G, Mazzon E, Micali A, Caputi AP, Macarthur H, Salvemini D. (2000) Beneficial effects of peroxinitrite decomposition catalyst in a rat model of splanchnic artery occlusion and reperfusion. FASEB J. 14: 1061-1072.

27. Mullane KM, Kraemer R, Smith B. (1985) Myeloperoxidase activity as a quantitative assessment of neutrophil infiltration into ischemic myocardium. J. Pharmacol. Meth. 14: 157-167.

28. Ohkawa H, Ohishi N, Yagi K. (1979) Assay for lipid peroxides in animal tissues by thiobarbituric acid reaction. Anal. Biochem. 95: 351-358.

29. Szabó C, Thiemermann C, Wu CC, Perretti M, Vane JR. (1994) Inhibition of nitric oxide synthase induction by endogenous glucocorticoids accounts for endotoxin tolerance in vivo. Proc. Natl. Acad. Sci. U.S.A. 91: 271-275.

30. Cuzzocrea S, Santagati S, Sautebin L, et al. (2000) 17betaestradiol antiinflammatory activity in carrageenan-induced pleurisy. Endocrinology 141: 1455-1463. 
31. Poli V, Balena R, Fattori E, et al. (1994) Interleukin-6 deficient mice are protected from bone loss caused by estrogen depletion. EMBO J. 13: 1189-1196.

32. Ito I, Hayashi T, Yamada K, Kuzuya M, Naito M, Iguchi A. (1995) Physiological concentration of estradiol inhibits polymorphonuclear leukocyte chemotaxis via a receptor mediated system. Life Sci. 56: 2247-2253.

33. Lefer AM, Lefer DJ. (1993) Pharmacology of the endothelium in ischemia-reperfusion and circulatory shock. Annu. Rev. Pharmacol. Toxicol. 33: 71-90.

34. Geng JG, Bevilacqua MP, Moore KL, et al. (1990) Rapid neutrophil adhesion to activated endothelium mediated by GMP140. Nature 343: 757-760.

35. Butcher EC. (1993) Specificity of leukocyte-endothelial interactions and diapedesis: physiologic and therapeutic implications of an active decision process. Res. Immunol. 144: 695-698.

36. Koizumi M, King N, Lobb R, Benjamin C, Podolsky DK. (1992) Expression of vascular adhesion molecules in inflammatory bowel. Gastroenterology 103: 840-847.

37. Boyd AW, Wawryk SO, Burns GF, Fecondo JV. (1988) Intercellular adhesion molecule-1 (ICAM-1) has a central role in cell-cell contact-mediated immune mechanism. Proc. Natl. Acad. Sci. U.S.A. 85: 3095-3103.

38. Fuster V, Poon M, Willerson JT. (1998) Learning from the transgenic mouse : endothelium, adhesive molecules, and neointimal formation. Circulation 97: 16-18.

39. Warren JS, Yabroff KR, Mandel DM, Johnson KJ, Ward PA. (1990) Role of $\mathrm{O}_{2}-$ in neutrophil recruitment into sites of dermal and pulmonary vasculitis. Free Radic. Biol. Med. 8: 163-172.

40. Beckman JS. (1996) Oxidative damage and tyrosine nitration from peroxynitrite. Chem. Res. Toxicol. 9: 836-844.

41. Eiserich JP, Hristova M, Cross CE, et al. (1998) Formation of nitric oxide-derived inflammatory oxidants by myeloperoxidase in neutrophils. Nature 391: 393-397.

42. Szabo C, Virag L, Cuzzocrea S, et al. (1998) Protection against peroxynitrite-induced fibroblast injury and arthritis development by inhibition of poly (ADP-ribose) synthase. Proc. Natl. Acad. Sci. U.S.A. 95: 3867-3872.

43. Cuzzocrea S, Zingarelli B, Gilad E, Hake P, Salzman AL, Szabo C. (1998) Protective effects of 3-aminobenzamide, an inhibitor of poly (ADP-ribose) synthase in a carrageenan-induced model of local inflammation. Eur. J. Pharmacol. 342: 67-76.
44. Cuzzocrea S, Caputi AP, Zingarelli B. (1998) Peroxynitritemediated DNA strand breakage activates poly (ADP-ribose) synthetase and causes cellular energy depletion in carrageenaninduced pleurisy. Immunology 93: 96-101.

45. Reif DW. (1992) Ferritin as a source of iron for oxidative damage. Free Radic. Biol. Med. 12: 417-427.

46. Szabó C, Dawson VL. (1998) Role of poly(ADP-ribose) synthetase in inflammation and ischaemia-reperfusion. Trends Pharmacol. Sci. 19: 287-298.

47. Zancan V, Santagati S, Bolego C, Vegeto E, Maggi A, Puglisi L. (1999) 17-Beta-estradiol decreases nitric oxide synthase II synthesis in vascular smooth muscle cells. Endocrinology 140 2004-2009.

48. Sunyer T, Lewis J, Collin-Osdoby P, Osdoby P. (1999) Estrogen's bone-protective effects may involve differential IL-1 receptor regulation in human osteoclast-like cells J. Clin. Invest. 103: 1409-1418.

49. Vegeto E, Pollio G, Ciana P, Maggi A. (2000) Estrogen blocks inducible nitric oxide synthase accumulation in LPS-activated microglia cells. Exp Geront. 35: 1309-1316.

50. Deshpande RR, Chapman JC, Michael SD. (1997) The anovulation in female mice resulting from postnatal injections of estrogen is correlated with altered levels of CD8 + lymphocytes. Am. J. Reprod. Immunol. 38: 114-120.

51. Morishita M, Miyagi M, Iwamoto Y. (1999) Effects of sex hormones on production of interleukin-1 by human peripheral monocytes. J. Periodontol. 70: 757-760.

52. Morisset S, Patry C, Lora M, de Brum-Fernandes AJ. (1998) Regulation of cyclooxygenase-2 expression in bovine chondrocytes in culture by interleukin lalpha, tumor necrosis factor-alpha, glucocorticoids, and 17beta-estradiol. J. Rheumatol. 25: 1146-1153.

53. Dodel RY, Du KR, Bales F, Gao, Paul S. (1999) Sodium salicylate and $17 ß$-estradiol attenuate nuclear transcription factor NF-B translocation in cultured rat astroglial cultures following exposure to amyloid Aß1-40 and lipopolysaccharides. J. Neurochem. 73: 1453-1460.

54. Oelzner P, Franke S, Muller A, Hein G, Stein G. (1999) Relationship between soluble markers of immune activation and bone turnover in post-menopausal women with rheumatoid arthritis. Rheumatology 38: 841-847.

55. Buyon JP. (1998) Hormone replacement therapy in postmenopausal women with systemic lupus erythematosus. J. Am. Med. Womens Assoc. 53: 13-17. 